\title{
Prevalence of Intracranial Aneurysms in Patients with Aortic Aneurysms
}

\author{
(D) A. Rouchaud, (D) M.D. Brandt, (D)A.M. Rydberg, (D) R. Kadirvel, (D) K. Flemming, DD.F. Kallmes, and (D) Wrinjikji
}

\begin{abstract}
BACKGROUND AND PURPOSE: Previous studies have suggested an association between aortic aneurysms and intracranial aneurysms with a higher prevalence of intracranial aneurysms in patients with aortic aneurysms. The aims of the present study were to evaluate the incidence of intracranial aneurysms in a large cohort of patients with aortic aneurysms and to identify potential risk factors for intracranial aneurysms in this population.
\end{abstract}

MATERIALS AND METHODS: We included all patients with aortic aneurysms (either abdominal and/or thoracic) who had available cerebral arterial imaging and were seen at our institution during a 15-year period. We identified patients with intracranial aneurysms. Patient demographics, comorbidities, and aortic aneurysm and intracranial aneurysm sizes and locations were analyzed. Univariate analysis was performed with a $\chi^{2}$ test for categoric variables and a Student $t$ test or ANOVA for continuous variables.

RESULTS: A total of 1081 patients with aortic aneurysms were included. Of them, 440 (40.7\%) had abdominal aortic aneurysms, 446 (41.3\%) had thoracic aortic aneurysms, and 195 (18.0\%) had both abdominal aortic and thoracic aortic aneurysms. The overall prevalence of associated intracranial aneurysms in patients with aortic aneurysms was $11.8 \%$ (128/1081), with 12.7\% (56/440), 10.8\% (48/446), and 12.3\% (24/195), respectively, in patients with abdominal aortic aneurysms, thoracic aortic aneurysms, and both thoracic aortic aneurysms and abdominal aortic aneurysms. Female patients had a higher risk of associated intracranial aneurysms $(\mathrm{OR}=2.08 ; 95 \% \mathrm{Cl}, 1.49-3.03 ; P=$ .0002). There was a slight association between abdominal aortic aneurysm size and the prevalence of intracranial aneurysms (OR $=1.02$; $95 \% \mathrm{Cl}, 1.01-1.03 ; P=.045)$. There was no significant association between the locations of the aortic and intracranial aneurysms $(P=.93)$.

CONCLUSIONS: The prevalence of intracranial aneurysms is high in patients with aortic aneurysms. Further studies examining the role and cost-effectiveness of intracranial aneurysm screening in patients are warranted.

ABBREVIATIONS: $\mathrm{AA}=$ aortic aneurysm; $\mathrm{AAA}=$ abdominal aortic aneurysm; $\mathrm{ADPKD}=$ autosomal dominant polycystic kidney disease; $I \mathrm{~A}=$ intracranial aneurysm; TAA $=$ thoracic aortic aneurysm

T he overall prevalence of unruptured intracranial aneurysms (IAs) in the general population is estimated as $3.2 \% .^{1}$ The overall prevalence of aortic aneurysms (AAs), with both thoracic (TAAs) and abdominal (AAAs) aortic aneurysms, is estimated at around $1 \%-2 \%$ in the general population with up to $10 \%$ prevalence in older age groups. ${ }^{2}$ Previous studies have identified a link between intracranial aneurysms and aortic diseases such as coarctation of the aorta or a bicuspid aortic valve. ${ }^{3-6}$ A few studies have

Received November 20, 2015; accepted after revision February 22, 2016

From the Departments of Radiology (A.R., M.D.B., A.M.R., R.K., D.F.K., W.B.) and Neurology (K.F.), Mayo Clinic, Rochester, Minnesota.

Aymeric Rouchaud received financial support from a research grant from the French Society of Radiology and the Thérèse and René Planiol Foundation.

Please address correspondence to Aymeric Rouchaud, MD, Department of Radiology, Mayo Clinic, 200 First St SW, Rochester, MN 55901; e-mail: aymeric.

rouchaud@gmail.com

http://dx.doi.org/10.3174/ajnr.A4827 reported an association between abdominal aortic aneurysms and thoracic aortic aneurysms and IAs, with a higher prevalence of IA in patients with aortic aneurysms. ${ }^{6-14}$ However, contrary to other pathologies such as autosomal dominant polycystic kidney disease (ADPKD), which is associated with IA in $12.4 \%$ of cases, no systematic screening for IA is proposed for patients with AA. ${ }^{15}$ The aims of the present study were to evaluate the prevalence of IA in a large cohort of patients with AA and to identify potential risk factors for IA in this population.

\section{MATERIALS AND METHODS Patient Population}

Following institutional review board approval, we performed a search of our imaging and clinical data base for all patients with clinical or radiologic notes between January 2001 and June 2015 with the key words "aortic aneurysms," "abdominal aortic aneurysm," and "thoracic aortic aneurysm." We selected patients who 
Table 1: Summary of baseline characteristics by AA type

\begin{tabular}{|c|c|c|c|c|c|}
\hline & All Patients & AAA & TAA & AAA and TAA & $P$ \\
\hline No. (\%) & 1081 & $440(40.7)$ & $446(41.3)$ & $195(18.0)$ & - \\
\hline Mean age (yr) (SD) & $69.3(16.2)$ & $77.8(9.3)$ & $62.2(17.0)$ & $70.8(16.7)$ & $<.0001$ \\
\hline Mean max AAA diameter & $49.3(14.3)$ & 49.6 (14.4) & - & $48.5(14.0)$ & - \\
\hline Mean max TAA diameter & $50.2(11.1)$ & - & $48.5(9.2)$ & $54.5(13.8)$ & - \\
\hline \multicolumn{6}{|l|}{ Sex } \\
\hline Male & $800(74.0)$ & $348(79.1)$ & $310(69.5)$ & $142(72.8)$ & .005 \\
\hline Female & $281(26.0)$ & $92(20.9)$ & $136(30.5)$ & $53(27.2)$ & \\
\hline \multicolumn{6}{|l|}{ Comorbidities } \\
\hline Stroke/TIA & $509(47.1)$ & $236(53.6)$ & $163(36.6)$ & $110(56.4)$ & $<.0001$ \\
\hline Coronary artery disease & $510(47.3)$ & $278(63.3)$ & $125(28.1)$ & $107(54.9)$ & $<.0001$ \\
\hline Hypertension & $855(79.2)$ & $394(89.8)$ & $283(63.5)$ & $178(91.3)$ & $<.0001$ \\
\hline Diabetes & $208(19.3)$ & 119 (27.2) & $56(12.6)$ & 33 (16.9) & $<.0001$ \\
\hline Hyperlipidemia & $743(68.8)$ & $369(84.1)$ & $228(51.1)$ & $146(74.9)$ & $<.0001$ \\
\hline Current/former smoker & $356(33.0)$ & $214(48.8)$ & $68(15.3)$ & $74(38.0)$ & $<.0001$ \\
\hline Bicuspid aortic valve & $142(13.1)$ & $3(0.7)$ & $132(29.6)$ & $7(3.6)$ & $<.0001$ \\
\hline \multicolumn{6}{|l|}{ Imaging } \\
\hline MRA & $903(83.5)$ & $373(84.8)$ & $369(82.7)$ & $161(82.6)$ & .66 \\
\hline CTA & $249(23.0)$ & $94(21.4)$ & $104(23.3)$ & $51(26.2)$ & .52 \\
\hline DSA & $114(10.5)$ & $55(12.5)$ & $40(9.0)$ & $19(9.7)$ & .34 \\
\hline No. (\%) with intracranial aneurysms & $128(11.8)$ & $56(12.7)$ & $48(10.8)$ & $24(12.3)$ & .44 \\
\hline No. of aneurysms & 172 & 70 & 65 & 37 & - \\
\hline $\begin{array}{l}\text { No. }(\%) \text { of patients with multiple } \\
\text { aneurysms }\end{array}$ & $30(23.4)$ & $14(25.0)$ & $10(15.4)$ & $6(25.0)$ & .34 \\
\hline Mean size & $6.0(5.8)$ & $5.4(4.4)$ & $6.3(6.5)$ & $7.1(7.2)$ & .54 \\
\hline \multicolumn{6}{|l|}{ Location } \\
\hline ICA & $93(54.1)$ & $36(51.4)$ & $34(52.3)$ & $23(62.2)$ & .67 \\
\hline ACA & $16(9.3)$ & $7(10.0)$ & $7(10.8)$ & $2(5.4)$ & \\
\hline AcomA & $16(9.3)$ & $5(7.1)$ & $8(12.3)$ & $3(8.1)$ & \\
\hline MCA & $24(14.0)$ & $12(17.1)$ & $7(10.8)$ & $5(13.5)$ & \\
\hline Basilar artery & $13(7.6)$ & $8(11.4)$ & $3(4.6)$ & $2(5.4)$ & \\
\hline PICA & $5(2.9)$ & $1(1.4)$ & $2(3.1)$ & $2(2.7)$ & \\
\hline PCA & $4(2.3)$ & $1(1.4)$ & $3(4.6)$ & $0(0.0)$ & \\
\hline Vertebral artery & $2(1.2)$ & $0(0.0)$ & $1(1.5)$ & $1(2.7)$ & \\
\hline \multicolumn{6}{|l|}{ Location by anterior/posterior } \\
\hline Anterior & $148(86.0)$ & $60(83.3)$ & $56(86.2)$ & $32(86.5)$ & .99 \\
\hline Posterior & $24(14.0)$ & 10 (16.7) & 9 (13.8) & 5 (13.5) & \\
\hline
\end{tabular}

Note:-Max indicates maximum; ACA, anterior cerebral artery; AcomA, anterior communicating artery; PICA, posterior inferior cerebellar artery; PCA, posterior cerebral artery.

were 18 years of age or older who had an aortic aneurysm and cerebral arterial imaging (CTA, MRA, or DSA). Patients with known connective tissue diseases (ie, Marfan, Ehlers-Danlos, and Loeys-Dietz syndromes) were excluded.

\section{Data Collection}

The diagnosis of AA was determined according to previous reports for each patient. The definition of an abdominal aortic aneurysm was a diameter of $\geq 3.5 \mathrm{~cm}$, and the diameter of a thoracic aortic aneurysm was $\geq 4.5 \mathrm{~cm}$. The location of the AA (TAA, AAA, or both) and the size of the aneurysms were retrieved from available reports. In case the size was not reported, a radiologist measured the maximum aneurysm diameter on available examinations (CT or MR imaging). The primary outcome of this study was the prevalence of saccular intracranial aneurysms. Head CTA, MRA, and DSA radiology reports of patients with AA read by board-certified neuroradiologists were queried for the terms "aneurysm," "dilatation," or "saccular." All reports that did not have one of these terms were considered negative for aneurysms. Among those that did have a mention of the terms in their radiology reports, imaging was further evaluated to confirm the presence, location, and size of an intracranial aneurysm. This was performed by a neuroradiologist with 4 years of training. Patients with dissecting and fusiform aneurysms were excluded because these lesions are associated with a distinct natural history and pathophysiology compared with saccular aneurysms (20 patients). Partially thrombosed aneurysms were included in this study. Patients undergoing CTA evaluation had CT angiography on either 16-, 32-, or 64-section CT scanners. MR imaging and MRA were performed on 1.5T or 3T scanners. Each aneurysm was described according to its location and maximum diameter.

In addition to the presence of a saccular aneurysm, we collected the following baseline data: age at diagnosis of the intracranial aneurysm, sex, hypertension, coronary artery disease, diabetes mellitus, previous or current tobacco use, bicuspid aortic valve, and hyperlipidemia.

\section{Statistical Analysis}

All categoric variables were analyzed by using a $\chi^{2}$ test. All continuous variables were analyzed by using a Student $t$ test or ANOVA. We performed a subgroup analysis of AA location (ie, TAA, AAA, or both TAA and AAA). We also determined whether any of the abovementioned baseline characteristics were associated with the presence of intracranial aneurysms. Odds ratios and their associated 95\% confidence intervals were calculated. To determine which variables, if any, were independently associated with the presence of an intracranial aneurysm, we performed a multivariate analysis, adjusting for aortic aneurysm type and any variables that were associated with the presence of aneurysms on univariate analysis (ie, carotid artery disease, female sex, and aortic aneurysm size). All statistical analyses were performed by using JMP 12.0 (SAS Institute, Cary, North Carolina).

\section{RESULTS}

\section{Baseline Characteristics}

A total of 1081 patients with AA were included. Of them, 440 (40.7\%) had AAAs, 446 (41.3\%) had TAAs, and 195 (18.0\%) had both AAAs and TAAs. Baseline demographics and aneurysm characteristics according to the AA location are presented in Table 1.

The mean age of all patients was $69.3 \pm 16.2$ years, with $74.0 \%$ (800/1081) of patients being men. The mean maximal diameters of the AAs were $49.3 \pm 14.3 \mathrm{~mm}$ and $50.2 \pm 11.1 \mathrm{~mm}$ for AAAs and TAAs, respectively. There were statistically significant differences regarding the comorbidities and cardiovascular risk factors between the AAA and TAA groups, with a higher prevalence of stroke/TIA, coronary artery disease, hypertension, diabetes, hyperlipidemia, and smoking history in the AAA group than in the TAA group (all $P$ values $<.01$ ), demonstrating that AAAs are 
Table 2: Risk factors for intracranial aneurysms in patients with aortic aneurysms

\begin{tabular}{|c|c|c|c|c|c|c|c|c|}
\hline & \multicolumn{2}{|l|}{ All } & \multicolumn{2}{|c|}{ AAA Only } & \multicolumn{2}{|c|}{ TAA Only } & \multicolumn{2}{|c|}{ TAA and AAA } \\
\hline & OR $(95 \% \mathrm{CI})$ & $P$ & OR $(95 \% \mathrm{Cl})$ & $P$ & OR $(95 \% \mathrm{CI})$ & $P$ & OR $(95 \% \mathrm{Cl})$ & $P$ \\
\hline Age (1-yr increase) & $0.99(0.91-1.08)$ & .29 & $0.99(0.95-1.04)$ & .61 & $1.00(0.97-1.03)$ & .61 & $0.96(0.92-0.98)$ & .01 \\
\hline AAA size (mm increase) & $1.02(1.01-1.03)$ & .045 & $1.01(0.96-1.07)$ & .36 & - & - & $1.04(1.02-1.06)$ & .03 \\
\hline TAA size (mm increase) & $1.01(0.97-1.04)$ & .49 & - & - & $1.00(0.96-1.04)$ & .83 & $1.02(0.98-1.06)$ & .14 \\
\hline Female sex & $2.08(1.49-3.03)$ & .0002 & $1.31(0.68-2.51)$ & .42 & $2.32(1.26-4.26)$ & .006 & $4.74(1.95-11.50)$ & .0002 \\
\hline \multicolumn{9}{|l|}{ Comorbidities } \\
\hline Stroke/TIA & $0.83(0.58-1.20)$ & .035 & $0.61(0.35-1.07)$ & .08 & $1.40(0.76-2.57)$ & .27 & $0.51(0.21-1.21)$ & .12 \\
\hline CAD & $0.68(0.47-0.99)$ & .047 & $0.63(0.37-1.11)$ & .11 & $0.40(0.18-0.92)$ & .03 & $0.97(0.41-2.28)$ & .94 \\
\hline HTN & $0.93(0.60-1.46)$ & .76 & $0.64(0.28-1.46)$ & .29 & $0.96(0.51-1.77)$ & .88 & $1.06(0.23-4.94)$ & .94 \\
\hline DM & $0.85(0.52-1.39)$ & .52 & $0.70(0.36-1.38)$ & .34 & $0.43(0.13-1.45)$ & .16 & $2.30(0.87-6.08)$ & .13 \\
\hline HLP & $0.82(0.55-1.20)$ & .31 & $0.41(0.21-0.78)$ & .006 & $1.26(0.69-2.30$ & .54 & $0.63(0.25-1.58)$ & .32 \\
\hline Bicuspid aortic valve & $0.72(0.40-1.32)$ & .33 & NA & .84 & $0.59(0.29-1.23)$ & .16 & $5.96(1.25-28.50)$ & .01 \\
\hline Current/former smoker & $1.25(0.86-1.84)$ & .24 & $0.82(0.47-1.45)$ & .57 & $0.94(0.40-2.20)$ & .89 & $3.90(1.58-9.64)$ & .002 \\
\hline
\end{tabular}

Note:-CAD indicates carotid artery disease; HTN, hypertension; DM, diabetes mellitus; HLP, hyperlipidemia; NA, not applicable.

Table 3: Prevalence of aneurysms by comorbidity

\begin{tabular}{lcccc}
\hline & \multicolumn{4}{c}{ Aneurysm Prevalence (\%) } \\
\cline { 2 - 5 } & All Patients & AAA & TAA & AAA and TAA \\
\hline Sex & & & & \\
$\quad$ Male & $51 / 281(18.2)$ & $42 / 348(12.1)$ & $25 / 310(8.1)$ & $10 / 142(7.0)$ \\
$\quad$ Female & $77 / 800(9.6)$ & $14 / 92(15.2)$ & $23 / 136(16.9)$ & $14 / 53(26.4)$ \\
Comorbidities & & & & \\
$\quad$ Stroke/TIA & $55 / 509(10.8)$ & $24 / 236(10.2)$ & $21 / 163(12.9)$ & $10 / 110(9.1)$ \\
CAD & $50 / 510(9.8)$ & $30 / 278(10.8)$ & $7 / 125(5.6)$ & $13 / 107(12.2)$ \\
HTN & $100 / 855(11.7)$ & $48 / 394(12.2)$ & $30 / 283(10.6)$ & $22 / 178(12.4)$ \\
DM & $22 / 208(10.6)$ & $12 / 119(10.1)$ & $3 / 56(5.4)$ & $7 / 33(21.2)$ \\
HLP & $83 / 743(11.2)$ & $40 / 369(10.8)$ & $27 / 228(11.8)$ & $16 / 146(11.0)$ \\
Bicuspid aortic valve & $13 / 142(9.2)$ & $0 / 3(0.0)$ & $10 / 132(7.6)$ & $3 / 7(42.9)$ \\
Current/former smoker & $48 / 308(13.5)$ & $25 / 214(11.7)$ & $7 / 68(10.3)$ & $16 / 74(21.6)$ \\
\hline
\end{tabular}

Note:-CAD indicates carotid artery disease; HTN, hypertension; DM, diabetes mellitus; HLP, hyperlipidemia. increased prevalence of IAs $(\mathrm{OR}=1.02$; 95\% CI, 1.01-1.03; $P=.045)$. Among patients with only AAAs, no variables were associated with an increased prevalence of IAs. Among patients with TAAs, only female sex $(\mathrm{OR}=2.32 ; 95 \%$ CI, 1.26-4.26; $P=.006$ ) was associated with a higher risk of IA. No other variable, including the presence of a bicuspid valve, was associated with IAs. Among patients with both TAAs and AAAs, variables associated with IA formation were female sex $(\mathrm{OR}=4.74$; 95\% CI, 1.95-11.50; $P=.0002)$, the linked to cardiovascular risk factors. TAAs were strongly associated with bicuspid aortic valve $(P<.0001)$. Patients with TAAs or both TAAs and AAAs were significantly younger than patients with AAAs alone $(P<.0001)$.

\section{Prevalence and Risk Factors for Aneurysm}

Of the overall cohort, 128 patients $(11.8 \%)$ had IAs, with a total of 172 IAs. The mean size of the IAs was $6.0 \pm 5.8 \mathrm{~mm}$. The IAs were located in the anterior circulation in $86.0 \%(148 / 172)$ of cases.

IAs were identified in $12.7 \%$ (56/440), $10.8 \%$ (48/446), and $12.3 \%$ (24/195), respectively, in patients with AAAs, TAAs, and both AAAs and TAAs. There was no statistical difference across groups for the location of associated IAs $(P=.67)$, even when aneurysm locations were grouped into anterior or posterior cerebral circulation $(P=.93)$. Similarly, the sizes of IAs were not different across the various groups $(P=.54)$. The number of patients with multiple IAs was not different across the $3 \mathrm{AA}$ groups $(P=.34)$. The size of the AAAs or TAAs was not significantly associated with a higher prevalence of associated IAs in the different groups, except in the patients with both AAAs and TAAs and associated IAs who had larger AAAs than patients without associated IAs $(P=.003)$.

A summary of risk factors for intracranial aneurysms in patients with aortic aneurysms is provided in Table 2. Prevalences of intracranial aneurysms by comorbidity are provided in Table 3. Among all patients, female sex was associated with higher odds of an intracranial aneurysm $(\mathrm{OR}=2.08 ; 95 \% \mathrm{CI}, 1.49-3.03 ; P=$ .0002). In addition, increased AAA size was associated with an presence of a bicuspid valve $(\mathrm{OR}=5.96 ; 95 \% \mathrm{CI}, 1.25-28.50 ; P=$ $.01)$, and smoking history $(\mathrm{OR}=3.90 ; 95 \% \mathrm{CI}, 1.58-9.64 ; P=$ $.002)$.

On multivariate logistic regression analysis, adjusting for aortic aneurysm type, aortic aneurysm size, sex, and the presence of carotid artery disease, female sex was the only variable independently associated with the presence of intracranial aneurysms $(\mathrm{OR}=2.17 ; 95 \% \mathrm{CI}, 1.25-3.70 ; P=.006)$.

\section{Aneurysm Rupture}

Of the 128 patients with intracranial aneurysms in this study, 8 had aneurysm rupture (6.3\%). Five patients with ruptured aneurysms were men and 3 were women. Four had AAAs without TAAs, 2 had TAAs without AAAs, and 2 had both TAAs and AAAs. The mean size of the AAAs in the ruptured aneurysm population was $56 \pm 12.2 \mathrm{~mm}$, and the mean size of the TAAs was $41.5 \pm 3.4 \mathrm{~mm}$. Mean intracranial aneurysm size was $9.6 \pm 10.5$ $\mathrm{mm}$. Six ruptured aneurysms were located in the anterior circulation, and 2 were located in the posterior circulation.

\section{DISCUSSION}

The present study demonstrates, in a large cohort of patients with $\mathrm{AA}$, that the prevalence of associated IAs is high, with a global prevalence of $11.8 \%$. This prevalence is about 4 times higher than that in the general population. Furthermore, this association is higher in women with TAAs. Female sex was the only variable independently associated with IAs in the AA population. There was no significant relation between the AA type and the pres- 
ence of IAs. We also identified patients with coronary artery disease and hyperlipidemia having lower odds of IA. We did not find any significant association between the AA size and the presence of an IA or its location. These results are important because they suggest that further studies examining the role of IA screening in patients with AAA and TAA are warranted.

Our results are in accordance with a recent study published by Shin et al, ${ }^{14}$ who reported a $11.6 \%$ prevalence of IAs in a cohort of 611 patients with AAs. In a small study, Kuzmik et al ${ }^{13}$ observed a 9.0\% prevalence of IAs in a series of 212 patients with TAAs. Unlike the study of Shin et al, we found that female sex was a significant risk factor for the presence of IAs, and we did not find any association between AA type and IA size or location. We did not find any higher risk for IAs in patients with AAs with hypertension or smoking history, contrary to the findings of Kuzmik et al. ${ }^{13}$

The present results suggest potential common pathophysiologic mechanisms for IA and AA. However, TAA and AAA have different origins, risk factors, and pathomechanisms. ${ }^{16}$ AAAs are related to cardiovascular risk factors, ${ }^{2}$ as confirmed in our cohort, with significantly more patients with stroke/TIA, coronary artery disease, hypertension, diabetes, hyperlipidemia, and smoking history in the AAA group than in the TAA group. On the contrary, TAAs and IAs are mostly considered nonatherosclerotic arteriopathies, even though they share some common risk factors with AAAs, such as hypertension or tobacco use. ${ }^{1,11,14,16,17}$ TAAs usually appear in younger patients. However, the present study shows that whatever the location of the AA (either TAA or AAA), there is a high prevalence of associated IAs that appears to be independent of cardiovascular risk factors. A potential explanation is that the aorta and intracranial arteries embryologically originate from the neural crest cells, and some anomalous development of these cells (neurocristopathy) could explain the susceptibility for both AA and IA. ${ }^{18-20}$ However, despite the origin and susceptibility factors for AA and IA, their origin is probably a combination of genetic and environmental factors.

Furthermore, our study identified a prevalence of IAs in the AA population 4 times higher than in the general population. This is very important and should be taken into account when considering patients with AAs for a systematic screening to identify IAs. Indeed, in patients with autosomal dominant polycystic kidney disease, the prevalence of associated IA was around $10 \%$, with a 4 times higher risk. ${ }^{15,17}$ According to this relative risk, some have advised a systematic screening with MRA for IA in ADPKD. ${ }^{21-26}$ However, to date, there is no proved benefit in morbidity, mortality, or reduction in subarachnoid hemorrhage among patients with ADPKD screened for IA, ${ }^{27}$ potentially due to other factors such as a higher risk of IA treatment in patients with ADPKD, as recently suggested by Rozenfeld et al. ${ }^{28,29}$ In our study, the IA prevalence in patients with AAs was similar to the IA prevalence in the ADPKD population. Our results suggest that future prospective studies examining the role of IA screening in patients with AAs could be warranted, especially in female patients with TAAs. $^{28,29}$

Also, there is a high association of IA with AA in the perioperative care of AA. Indeed, the pressure on the cerebral arteries varies substantially due to cross-clamping and declamping of the aorta during aortic surgery. ${ }^{30}$ There is a theoretic potential risk of IA rupture with increasing cerebral perfusion pressure by occluding the aorta, albeit temporarily. ${ }^{3}$ Surgeons should be aware of the presence of an IA to avoid large pressure variations. In addition, measures such as strict postoperative blood pressure control can also be taken with a known IA, to reduce the risk of rupture. ${ }^{13}$ Systematic identification of an IA in patients with AAs seems beneficial to prevent IA rupture.

\section{Limitations}

Our study is limited by its retrospective nature. We could not exclude a potential selection bias because patients with previous neurologic symptoms were more likely to have cerebral arterial imaging available and to be included in the present study; this feature could create the possibility of skewing the data toward a greater prevalence of IA. It is also possible that we underestimated the prevalence of IA in this population. We did not search for the indication of arterial intracranial imaging, which could potentially introduce a selection bias if the imaging was performed to search for an intracranial aneurysm. We also did not document the time of IA detection in relation to the AA detection. There is also a limitation in the ascertainment of the smoking status because we did not differentiate patients with previous or current smoking history and did not perform any analysis regarding the pack-year consumption. Also for the TAA, we did not separate ascending and descending TAAs, which could potentially have different results regarding the incidence of associated IAs. Our study did not find any significant association between AA and IA locations, which could potentially be due to the low statistical power of multiple subgroup analyses; however, the global population of our cohort was the largest compared with previously published series.

\section{CONCLUSIONS}

This study shows that in a large AA cohort, prevalence of IAs is high in patients with AA. Women were at higher risk for concomitant IA. Further studies are needed to determine whether patients with known AAs should be screened for IAs.

Disclosures: Ramanathan Kadirvel—UNRELATED: Grants/Grants Pending: National Institutes of Health.* David F. Kallmes-UNRELATED: Board Membership: GE Healthcare, ${ }^{*}$ Comments: Cost-Effectiveness Board; Consultancy: Medtronic, ${ }^{*}$ Comments: planning and implementing clinical trials; Grants/Grants Pending: Medtronic, ${ }^{*}$ MicroVention, ${ }^{\star}$ Codman, ${ }^{\star}$ NeuroSigma, ${ }^{*}$ Sequent Medical, ${ }^{\star}$ Surmodics. * Money paid to the institution.

\section{REFERENCES}

1. Vlak MH, Algra A, Brandenburg R, et al. Prevalence of unruptured intracranial aneurysms, with emphasis on sex, age, comorbidity, country, and time period: a systematic review and meta-analysis. Lancet Neurol 2011;10:626-36 CrossRef Medline

2. Svensjo S, Bjorck M, Gürtelschmid M, et al. Low prevalence of abdominal aortic aneurysm among 65-year-old Swedish men indicates a change in the epidemiology of the disease. Circulation 2011; 124:1118-23 CrossRef Medline

3. Curtis SL, Bradley M, Wilde P, et al. Results of screening for intracranial aneurysms in patients with coarctation of the aorta. AJNR Am J Neuroradiol 2012;33:1182-86 CrossRef Medline

4. Connolly HM, Huston J 3rd, Brown RD Jr, et al. Intracranial aneurysms in patients with coarctation of the aorta: a prospective mag-

AJNR Am J Neuroradiol 37:1664-68 Sep 2016 www.ajnr.org 1667 
netic resonance angiographic study of 100 patients. Mayo Clin Proc 2003;78:1491-99 CrossRef Medline

5. Schievink WI, Raissi SS, Maya MM, et al. Screening for intracranial aneurysms in patients with bicuspid aortic valve. Neurology 2010; 74:1430-33 CrossRef Medline

6. Shin YW, Jung KH, Kim JM, et al. Echocardiographic evidence of innate aortopathy in the human intracranial aneurysm. PLoS One 2014;9:e100569 CrossRef Medline

7. Fields WS, Gonzalez-Angulo A. Multiple aneurysmal dilatations of cerebral and peripheral arteries. Tex Med 1965;61:899-905 Medline

8. Kanai $\mathrm{H}$, Umezu M, Koide $\mathrm{K}$, et al. Ruptured intracranial aneurysm associated with unruptured abdominal aortic aneurysm: case report. Neurol Med Chir (Tokyo) 2001;41:260-63 CrossRef Medline

9. Kubo $\mathrm{S}$, Nakagawa $\mathrm{H}$, Imaoka S. Systemic multiple aneurysms of the extracranial internal carotid artery, intracranial vertebral artery, and visceral arteries: case report. Neurosurgery 1992;30:600-02 CrossRef Medline

10. Moore MT. Multiple cerebral aneurysms in a patient with an abdominal aortic aneurysm: report of a case. J Neurosurg 1965;23: 626-29 CrossRef Medline

11. Southerland AM, Meschia JF, Worrall BB. Shared associations of nonatherosclerotic, large-vessel, cerebrovascular arteriopathies: considering intracranial aneurysms, cervical artery dissection, Moyamoya disease and fibromuscular dysplasia. Curr Opin Neurol 2013;26:13-28 CrossRef Medline

12. Miyazawa N, Akiyama I, Yamagata Z. Risk factors for the association of intracranial and aortic aneurysms. Acta Neurochir (Wien) 2007; 149:221-29; discussion 229 CrossRef Medline

13. Kuzmik GA, Feldman M, Tranquilli M, et al. Concurrent intracranial and thoracic aortic aneurysms. Am J Cardiol 2010;105:417-20 CrossRef Medline

14. Shin YW, Jung KH, Moon J, et al. Site-specific relationship between intracranial aneurysm and aortic aneurysm. Stroke 2015;46: 1993-96 CrossRef Medline

15. Xu HW, Yu SQ, Mei CL, et al. Screening for intracranial aneurysm in $\mathbf{3 5 5}$ patients with autosomal-dominant polycystic kidney disease. Stroke 2011;42:204-06 CrossRef Medline

16. Norman PE, Powell JT. Site specificity of aneurysmal disease. Circulation 2010;121:560-68 CrossRef Medline

17. Rinkel GJ, Djibuti M, Algra A, et al. Prevalence and risk of rupture of intracranial aneurysms: a systematic review. Stroke 1998;29:251-56 CrossRef Medline

18. Noisa P, Raivio T. Neural crest cells: from developmental biology to clinical interventions. Birth Defects Res C Embryo Today 2014;102: 263-74 CrossRef Medline

19. Weston JA, Thiery JP. Pentimento: neural crest and the origin of mesectoderm. Dev Biol 2015;401:37-61 CrossRef Medline

20. Sattur M, Pines AR, Bendok B. Thinking from the heart: neurocristopathy, aortic abnormalities, and intracranial aneurysms. World Neurosurg 2016;85:25-27 CrossRef Medline

21. Wiebers DO, Torres VE. Screening for unruptured intracranial aneurysms in autosomal dominant polycystic kidney disease. $N$ Engl J Med 1992;327:953-55 CrossRef Medline

22. Huston J 3rd, Torres VE, Wiebers DO, et al. Follow-up of intracranial aneurysms in autosomal dominant polycystic kidney disease by magnetic resonance angiography. J Am Soc Nephrol 1996;7: 2135-41 Medline

23. Chapman AB, Rubinstein D, Hughes R, et al. Intracranial aneurysms in autosomal dominant polycystic kidney disease. $N$ Engl J Med 1992;327:916-20 CrossRef Medline

24. Ruggieri PM, Poulos N, Masaryk TJ, et al. Occult intracranial aneurysms in polycystic kidney disease: screening with MR angiography. Radiology 1994;191:33-39 CrossRef Medline

25. Mariani L, Bianchetti MG, Schroth G, et al. Cerebral aneurysms in patients with autosomal dominant polycystic kidney disease: to screen, to clip, to coil? Nephrol Dial Transplant 1999;14:2319-22 CrossRef Medline

26. Huston J 3rd, Torres VE, Sulivan PP, et al. Value of magnetic resonance angiography for the detection of intracranial aneurysms in autosomal dominant polycystic kidney disease. J Am Soc Nephrol 1993;3:1871-77 Medline

27. Chapman AB, Devuyst O, Eckardt KU, et al; Conference Participants. Autosomal-dominant polycystic kidney disease (ADPKD): executive summary from a Kidney Disease-Improving Global Outcomes (KDIGO) Controversies Conference. Kidney Int 2015;88: 17-27 CrossRef Medline

28. Rozenfeld MN, Ansari SA, Mohan P, et al. Autosomal dominant polycystic kidney disease and intracranial aneurysms: is there an increased risk of treatment? AJNR Am J Neuroradiol 2016;37:290-93 CrossRef Medline

29. Niemczyk M. Treatment of unruptured intracranial aneurysms in autosomal dominant polycystic kidney disease: primum non nocere. AJNR Am J Neuroradiol 2016;37:294-95 CrossRef Medline

30. Liu G, Burcev I, Pott F, et al. Middle cerebral artery flow velocity and cerebral oxygenation during abdominal aortic surgery. Anaesth Intensive Care 1999;27:148-53 Medline 